\title{
A facile approach to synthesize dysprosium oxide nanoparticles
}

\author{
Amir Zelati · Ahmad Amirabadizadeh • \\ Amirhossein Hosseini
}

Received: 2 April 2014/ Accepted: 8 September 2014/Published online: 27 September 2014

(c) The Author(s) 2014. This article is published with open access at Springerlink.com

\begin{abstract}
In this report, $\mathrm{Dy}_{2} \mathrm{O}_{3}$ (dysprosia) nanoparticles were prepared by using the combustion method. The innovative aspect of this method is preparation of dysprosium oxide nanoparticles without applying calcination temperature. To study the effect of the heating and annealing on the structure of dysprosia, three different calcination temperatures, 450, 550, and $650{ }^{\circ} \mathrm{C}$ were applied on the no-calcined sample. TEM and X-ray diffraction XRD were used for characterization of the samples. Diffraction pattern of samples were achieved by selected area electron diffraction (SAED). XRD patterns show the desired cubic structure for all samples. The results of crystallite sizes, estimated by the broadening of XRD peaks, showed the size of crystallites in the range of 24-28 nm. TEM showed the average size of the particles in the range of $28-41 \mathrm{~nm}$.
\end{abstract}

Keywords Dysprosium Oxide nanoparticles · XRD . TEM $\cdot$ Combustion method $\cdot$ SAED

\section{Introduction}

Nanomaterials or nanostructured materials are the materials with structural features in between those of atoms/ molecules and bulk materials, with at least one dimension in the range of $1-100 \mathrm{~nm}(1 \mathrm{~nm}=10-9 \mathrm{~m})$ [1]. In this size range, the particles have a high proportion of atoms

A. Zelati $(\bowtie) \cdot$ A. Amirabadizadeh

Department of Physics, University of Birjand, Birjand, Iran e-mail: a_zelati@yahoo.com

\section{A. Hosseini}

Department of Chemistry, University of Birjand, Birjand, Iran located at its surface as compared to bulk materials, giving rise to unique physical and chemical properties that are totally different from their bulk counterparts [2]. The oxides of rare earth elements such as $\mathrm{Y}, \mathrm{Nd}, \mathrm{Sm}, \mathrm{Eu}$, Dy, and $\mathrm{La}$ are emerging as promising materials for a variety of applications in many different fields of modern technology [3] such as catalysts, high efficiency phosphors, and magnetic to dielectric formulations for multilayer ceramic capacitors [4, 5]. Dysprosium oxide or dysprosia with chemical composition $\mathrm{Dy}_{2} \mathrm{O}_{3}$, one of the rare earth oxide families, is a basic metal oxide and its properties are influenced by the preparation conditions. $\mathrm{Dy}_{2} \mathrm{O}_{3}$ is a white, slightly hygroscopic powder, and it is highly insoluble and thermally stable. Dysprosia has specialized uses in ceramics, glass, phosphors, lasers, and dysprosium metal halide lamps [6].

There are some different ways for synthesis of dysprosia nanoparticles like homogenous precipitation and wet chemical methods. In this paper, combustion method for the preparation of $\mathrm{Dy}_{2} \mathrm{O}_{3}$ nanoparticles is reported. This method is generally employed to prepare oxide materials. The process involves the exothermic reaction between an oxidizer such as metal nitrates and organic fuel, like urea $\left(\mathrm{H}_{2} \mathrm{NCONH}_{2}\right)$, carbohydrazide $\left(\mathrm{CO}\left(\mathrm{NHNH}_{2}\right)_{2}\right)$, or glycine $\left(\mathrm{C}_{2} \mathrm{H}_{5} \mathrm{NO}_{2}\right)$. The combustion reaction is initiated in a muffle furnace or on a hot plate at temperatures of the order of $500{ }^{\circ} \mathrm{C}$ or less. In a typical reaction, the precursor (mixture of water, metal nitrates, and fuel) on heating decomposes, dehydrates, and ruptures into a flame. The resultant product is a voluminous, foamy powder, which occupies the entire volume of the reaction vessel [1]. The chemical energy released from the exothermic reaction between the metal nitrates and fuel can rapidly heat the system to high temperatures without an external heat source. Nanomaterials synthesized by combustion route are 
generally homogeneous, contain fewer impurities, and have higher surface areas than powders prepared by conventional solid-state methods. The major advantage of this method is that large-scale production can be made at relatively low temperatures. This method is very flexible and promising as it is relatively simple, reproducible, and economically feasible. By using combustion route, for preparing $\mathrm{Dy}_{2} \mathrm{O}_{3}$, the final product is obtained in a very short time. The innovative aspect of this method is preparation of $\mathrm{Dy}_{2} \mathrm{O}_{3}$ nanoparticles without applying calcination temperature. Although the product of the combustion method with no calcination temperature was $\mathrm{Dy}_{2} \mathrm{O}_{3}$ nanoparticles, for further study on the effect of the heating and annealing on the structural and optical properties of dysprosia, three different calcination temperatures, $T=450,550$, and $650{ }^{\circ} \mathrm{C}$ were applied on the initial product (no-calcined sample). Samples structural and morphological properties are investigated via X-ray diffraction (XRD) and transmission electron microscopy (TEM).

\section{Experimental}

Samples preparation

In this research, $\mathrm{Dy}_{2} \mathrm{O}_{3}$ nanoparticles were prepared by combustion method using, dysprosium (III) nitrate pantahydrate with chemical composition $\mathrm{Dy}\left(\mathrm{NO}_{3}\right) \cdot 5 \mathrm{H}_{2} \mathrm{O}$ as starting material. Distilled water was used as the solvent and glycine with chemical formula $\mathrm{C}_{2} \mathrm{H}_{5} \mathrm{NO}_{2}$ as the fuel of the reaction. The $\mathrm{Dy}_{2} \mathrm{O}_{3}$ nanopowder synthesization by the combustion method is summarized in a flow chart shown in Fig. 1. Chemical reaction formula for preparing dysprosia is shown in relation 1 .

$$
\begin{aligned}
& 2 \mathrm{Dy}\left(\mathrm{NO}_{3}\right) \times 5 \mathrm{H}_{2} \mathrm{O}+3 \mathrm{C}_{2} \mathrm{H}_{5} \mathrm{NO}_{2}+3 \mathrm{H}^{+}+3 \mathrm{e}^{-} \\
& \quad \rightarrow \mathrm{Dy}_{2} \mathrm{O}_{3}+6 \mathrm{CO}_{2}+9 / 2 \mathrm{~N}_{2}+19 \mathrm{H}_{2} \mathrm{O}
\end{aligned}
$$

For preparing $10 \mathrm{~mL}$ dysprosium nitrate $3.5 \mathrm{~N}$ solution, 5.12 gr dysprosium (III) nitrate pantahydrate was solved in adequate amount of distilled water. After obtaining aqueous solution of the cation, $\left(\mathrm{Dy}^{3+}\right)$, glycine as the fuel for combustion was added to the solution. This liquid mixture was stirred for $30 \mathrm{~min}$ at about $40{ }^{\circ} \mathrm{C}$ on a hot plate. In the mean time, the furnace was heated to $300{ }^{\circ} \mathrm{C}$. Then the liquid mixture was placed inside the pre-heated $\left(300{ }^{\circ} \mathrm{C}\right)$ furnace for one hour. Combustion took place inside the furnace and the resultant product was a voluminous, foamy, and white powder, which occupies the entire volume of the reaction vessel. For studying the effect of calcination temperature, the resultant powder was divided to 4 segments. One remained

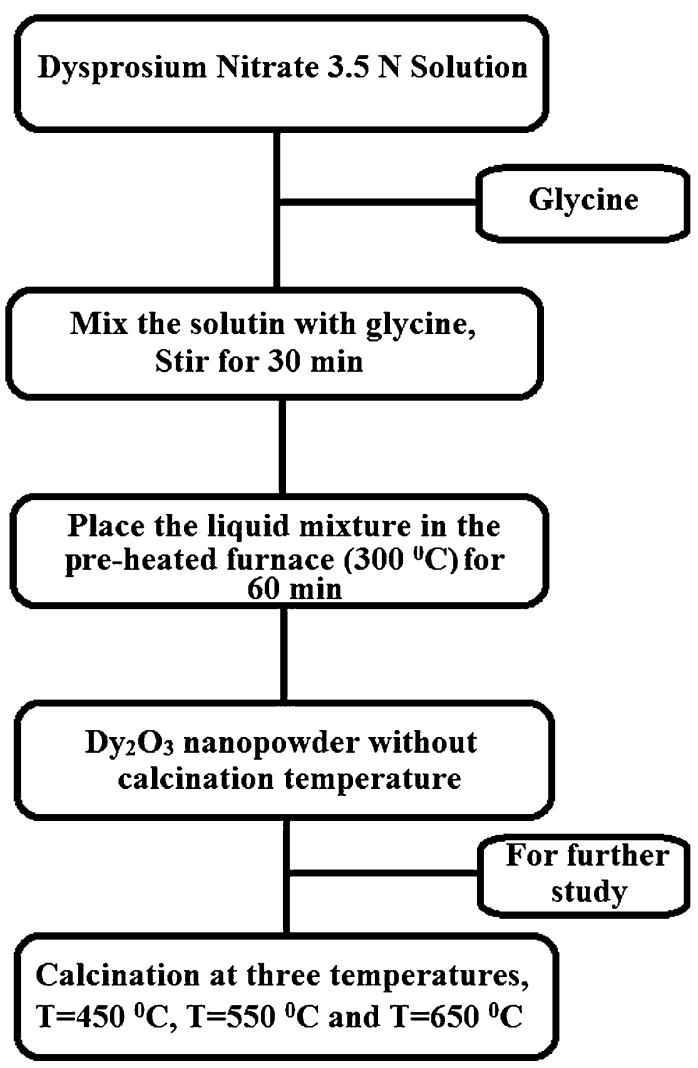

Fig. 1 Flow chart of $\mathrm{Dy}_{2} \mathrm{O}_{3}$ nanoparticles preparation by combustion process

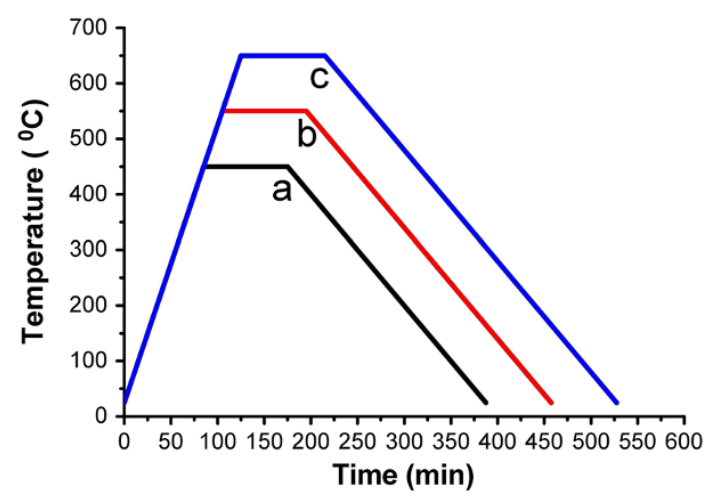

Fig. 2 Calcination diagram of, $a$ sample 2 , calcined at $450{ }^{\circ} \mathrm{C}, b$ sample 3 , calcined at $550{ }^{\circ} \mathrm{C}$, and $c$ sample 4 , calcined at $650{ }^{\circ} \mathrm{C}$

without calcination temperature (sample 1) and the rest were calcined at three different calcination temperatures $T=450{ }^{\circ} \mathrm{C}$ (sample 2), $T=550^{\circ} \mathrm{C}$ (sample 3), and $T=650^{\circ} \mathrm{C}$ (sample 4). Figure 2 shows the calcination diagrams of sample 2, 3, and 4. Each diagram consists of three stages. At the first stage, sample was heated to the calcination temperature with the ratio $5{ }^{\circ} \mathrm{C} / \mathrm{min}$ and then at the second stage, sample remained at calcination 
temperature for $90 \mathrm{~min}$ and at the final stage sample was cooled down to the room temperature with the ratio $2{ }^{\circ} \mathrm{C} / \mathrm{min}$.

\section{Samples preparation}

XRD and TEM were used for the characterization of the samples. XRD patterns of $\mathrm{Dy}_{2} \mathrm{O}_{3}$ nanoparticles prepared at various calcination temperatures were recorded by the $\mathrm{D} 8$ Advanced Brucker system using $\mathrm{CuK} \alpha(\lambda=0.154056 \mathrm{~nm})$ radiation with $2 \theta$ in the range $10-80^{\circ}$. The scanning rate was $0.060^{\circ} \mathrm{s}^{-1}$ in the $2 \theta$ range from 10 to $80^{\circ}$. The crystallite size $d_{\mathrm{XRD}}$ was estimated from the broadening of XRD peaks, using Scherrer's equation [7]:

$d_{\mathrm{XRD}}=\frac{K \lambda}{\beta \cos \theta}$,

where $\theta$ is the Bragg angle of diffraction lines, $K$ is a shape factor taken as $1, \lambda$ is the wavelength of incident $\mathrm{X}$-rays, and $\beta$ is the corrected full-width at half maximum (FWHM) given by:

$\beta^{2}=\beta_{\mathrm{m}}^{2}-\beta_{\mathrm{s}}^{2}$,

where $\beta_{\mathrm{m}}$ is the measured FWHM and $\beta_{\mathrm{s}}$ is the FWHM of a silicon standard with large crystallite size $(>150 \mathrm{~nm})$ that was used to determine the instrumental broadening.

TEM studies were carried out with an FEI Tecnai 20 transmission electron microscope with a field- emission source operating at $200 \mathrm{kV}$. The required sample for TEM analysis was prepared by dispersing the $\mathrm{Dy}_{2} \mathrm{O}_{3}$ nanopowders in acetone using an ultrasound bath. A drop of this dispersed suspension was put on to 200-mesh carboncoated $\mathrm{Cu}$ grid and then was dried in vacuum [8].

\section{Results and discussion}

X-ray diffraction

The phase identification of the no-calcined and calcined powders was performed using XRD. The average crystallite size of the powders was measured by X-ray linebroadening technique employing the Scherrer's formula (2). The XRD pattern of prepared $\mathrm{Dy}_{2} \mathrm{O}_{3}$ nanoparticles without applying calcination temperature is shown in Fig. 3. It is clear that the powders, which are not calcined, are crystalline without additional phase. Because of drastic increase of temperature in combustion process, there are strong picks of cubic structure of $\mathrm{Dy}_{2} \mathrm{O}_{3}$. Therefore, the innovative aspect of this method is preparation of $\mathrm{Dy}_{2} \mathrm{O}_{3}$ nanoparticles without applying calcination temperature. To study the effect of the heating and annealing on the structural and optical properties of dysprosia, three

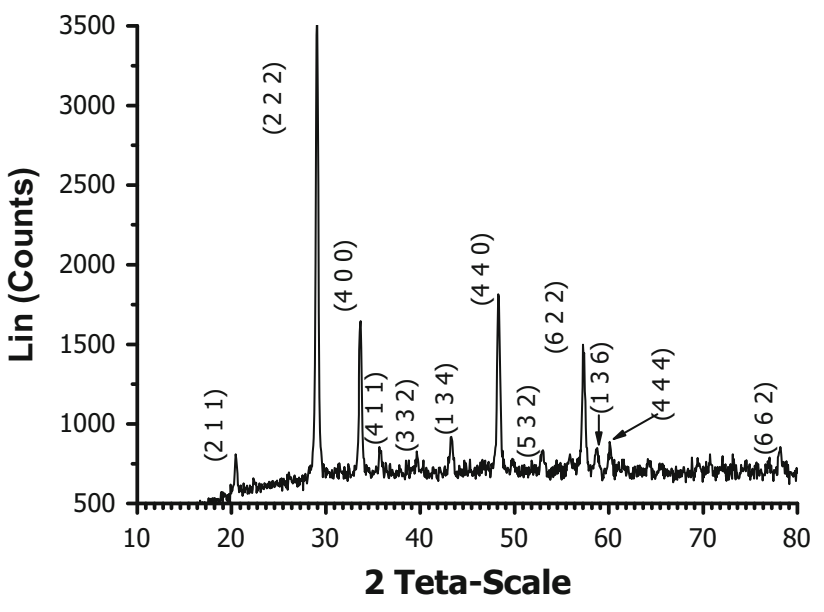

Fig. 3 XRD pattern of the no-calcined $\mathrm{Dy}_{2} \mathrm{O}_{3}$ (Sample 1) nanoparticle, Cubic structure, without additional phase

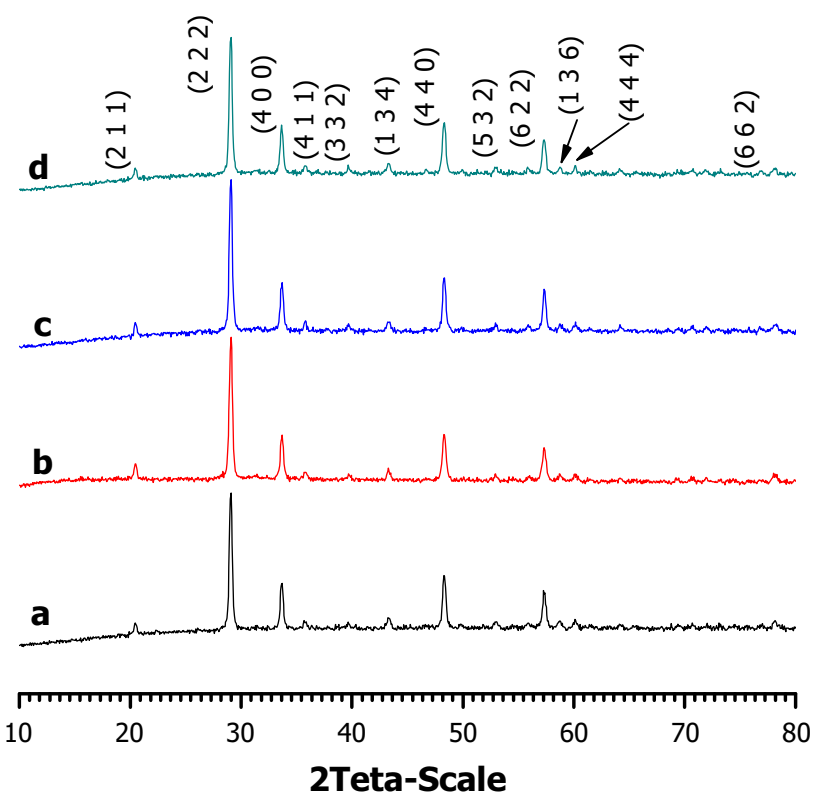

Fig. 4 XRD patterns of a no-calcined sample $\mathbf{b}$ calcined sample at $T=450{ }^{\circ} \mathrm{C}$, c calcined sample at $T=550{ }^{\circ} \mathrm{C}$, and $\mathbf{d}$ calcined sample at $T=650{ }^{\circ} \mathrm{C}$

different calcination temperatures, $T=450,550$, and $650{ }^{\circ} \mathrm{C}$ were applied on the no-calcined sample. The XRD patterns of the all samples are shown in Fig. 4. The Bragg's peaks of the crystallized powders correspond to each sample agree well with the reflections of pure cubic $\mathrm{Dy}_{2} \mathrm{O}_{3}$ single phase with $a=b=1.66500 \AA$. The XRD patterns at all samples show that the intensities of five basic peaks of the (222), (440), (400), (622), and (211) planes are more than the other peaks [8].

Table 1 shows the XRD parameters of $\mathrm{Dy}_{2} \mathrm{O}_{3}$ nanoparticles in various crystalline orientations without calcination temperature and at different calcination temperatures. As 
Table 1 The XRD parameters of nanoparticles in different crystallography orientation for no-calcined sample (sample 1) and for sample, which calcined at different calcination temperatures (Sample 1, 2 and 3). D (nm) and $<d>$ related to the Scherrer's formula (2)

\begin{tabular}{|c|c|c|c|c|c|c|c|}
\hline Sample & $h k l$ & $\begin{array}{l}2 \theta \\
(\mathrm{deg})\end{array}$ & $D(\AA)$ & $\begin{array}{l}\text { Intensity } \\
\text { Lin (Cps) }\end{array}$ & $\begin{array}{l}\text { FWHM } \\
2 \theta(\mathrm{deg})\end{array}$ & $\begin{array}{l}\mathrm{D}(\mathrm{nm}) \\
5 \% \text { error }\end{array}$ & $\begin{array}{l}<d>(\mathrm{nm}) \\
5 \% \text { error }\end{array}$ \\
\hline \multirow{5}{*}{$\begin{array}{l}\text { Sample } 1 \text { no calcined } \\
\text { sample }\end{array}$} & 222 & 29.068 & 3.0705 & 3571 & 0.369 & 24 & \multirow[t]{5}{*}{24} \\
\hline & 440 & 48.324 & 1.8818 & 1815 & 0.379 & 23 & \\
\hline & 400 & 33.671 & 2.6607 & 1646 & 0.355 & 25 & \\
\hline & 622 & 57.351 & 1.6057 & 1497 & 0.387 & 23 & \\
\hline & 211 & 20.463 & 4.3385 & 809 & 0.350 & 25 & \\
\hline \multirow{5}{*}{$\begin{array}{l}\text { Sample } 2 \text { calcined sample } \\
\text { at } T=450{ }^{\circ} \mathrm{C}\end{array}$} & 222 & 29.075 & 3.0698 & 3586 & 0.336 & 26 & \multirow[t]{5}{*}{25} \\
\hline & 440 & 48.323 & 1.8815 & 1518 & 0.393 & 22.5 & \\
\hline & 400 & 33.676 & 2.6605 & 1504 & 0.334 & 26.5 & \\
\hline & 622 & 57.351 & 1.6056 & 1236 & 0.406 & 22 & \\
\hline & 211 & 20.464 & 4.3387 & 895 & 0.319 & 28 & \\
\hline \multirow{5}{*}{$\begin{array}{l}\text { Sample } 3 \text { calcined sample } \\
\text { at } T=550{ }^{\circ} \mathrm{C}\end{array}$} & 222 & 29.464 & 3.0688 & 3942 & 0.323 & 27.5 & \multirow[t]{5}{*}{27} \\
\hline & 440 & 48.320 & 1.8811 & 1842 & 0.352 & 25 & \\
\hline & 400 & 33.683 & 2.6593 & 1754 & 0.323 & 27.5 & \\
\hline & 622 & 57.351 & 1.6053 & 1607 & 0.337 & 26 & \\
\hline & 211 & 20.464 & 4.3317 & 900 & 0.307 & 29 & \\
\hline \multirow{5}{*}{$\begin{array}{l}\text { Sample } 4 \text { calcined sample } \\
\text { at } T=650{ }^{\circ} \mathrm{C}\end{array}$} & 222 & 29.062 & 3.0706 & 3969 & 0.321 & 28 & \multirow[t]{5}{*}{28} \\
\hline & 440 & 48.309 & 1.8823 & 2152 & 0.359 & 25 & \\
\hline & 400 & 33.656 & 2.6606 & 1964 & 0.328 & 27 & \\
\hline & 622 & 57.321 & 1.6056 & 1790 & 0.329 & 27 & \\
\hline & 211 & 20.467 & 4.4 .34 & 1193 & 0.272 & 32.5 & \\
\hline
\end{tabular}

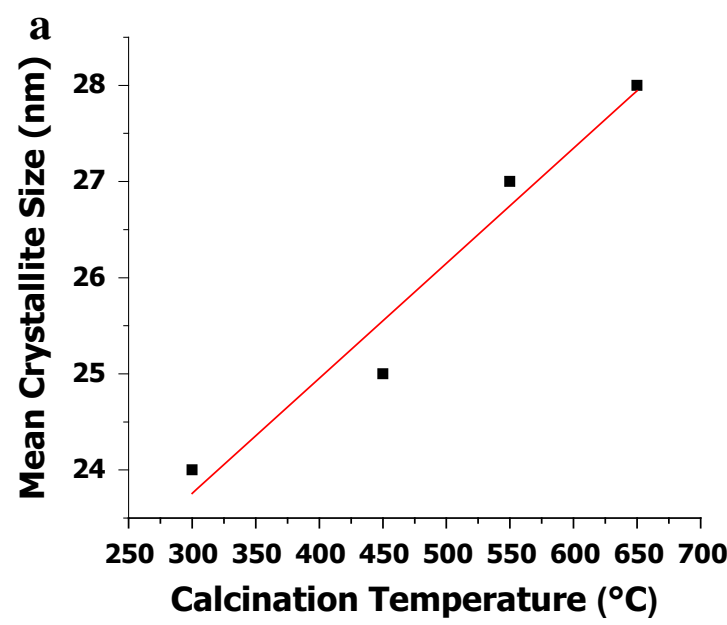

Fig. 5 a XRD results for variation of mean crystallite size against calcination temperature. The first point is for no-calcined sample and the temperature is the furnace temperature. b TEM results for

seen in Table 1, the width of the strongest peak and most of other picks decrease with the increase of the calcination temperature, which refers to the growth of crystal size. In addition, increase in calcination temperature leads to more crystalline structure [8].

The crystallite size was estimated from the broadening of XRD peaks, using Scherrer's formula (2) [7]. The results of the crystallite size are shown in Table 1 . As seen in

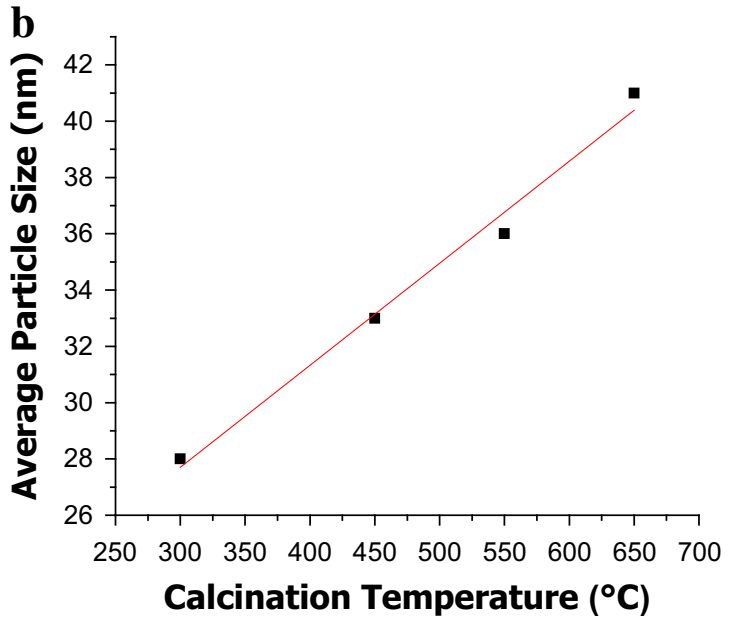

variation of average particle size against calcination temperature. The first point is for no-calcined sample and the temperature is the furnace temperature

Table 1 and Fig. 5a, the mean crystallite sizes $(<d>)$ are in the nanometric orders so XRD by using Scherrer's formula (2) confirms that the samples are in nanometric sizes. Scherrer's formula has an accurate result for single crystals while for poly-crystals the result is not accurate. The advantage of the Scherrer's formula is that the nanometric order of crystallite sizes can be estimated. It is observed from Table 1, the mean crystallite sizes increase with the 

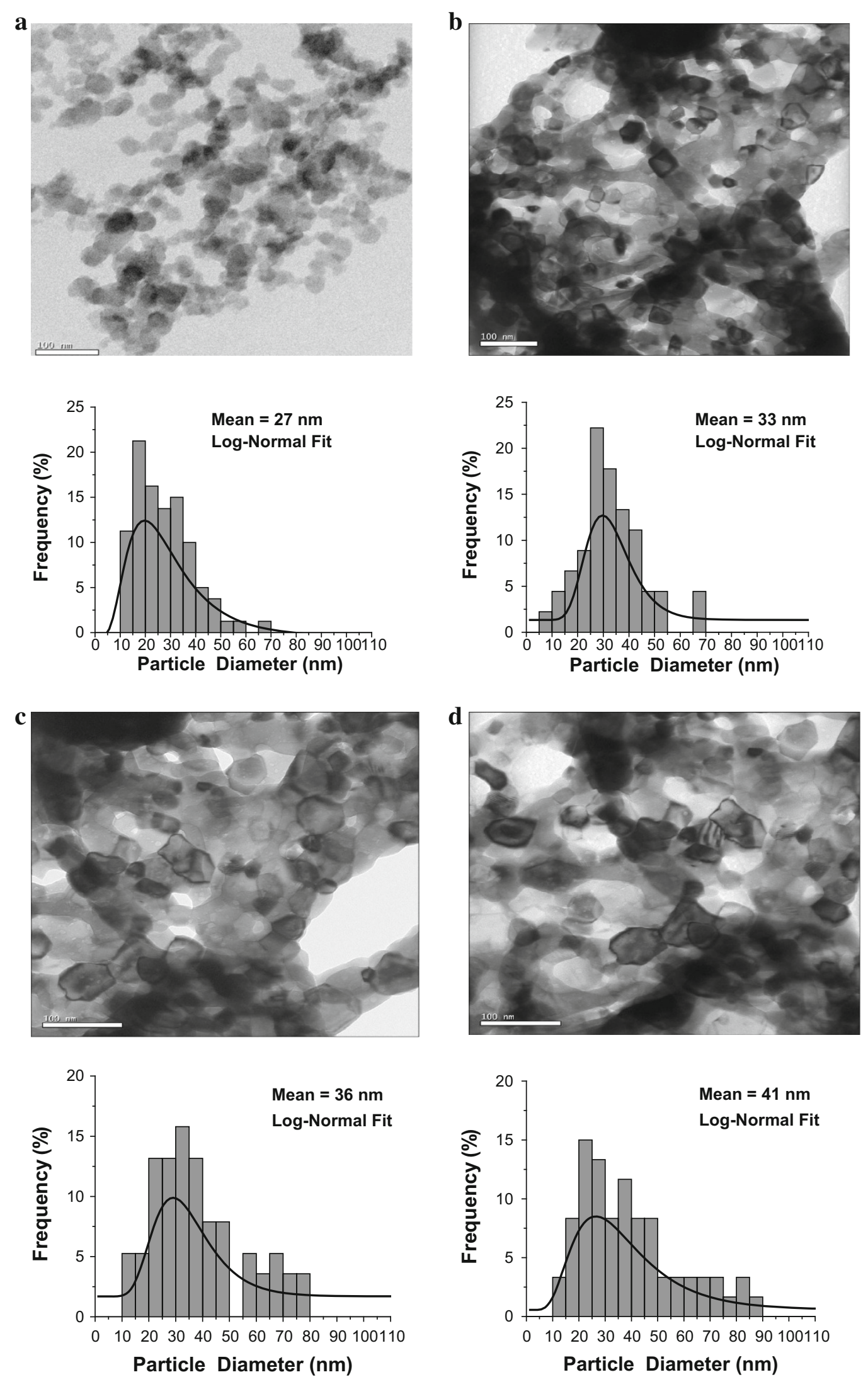

Fig. 6 TEM images of $\mathrm{Dy}_{2} \mathrm{O}_{3}$ prepared a without calcination temperature, b at $450{ }^{\circ} \mathrm{C}$ calcination temperature, $\mathbf{c}$ at $550{ }^{\circ} \mathrm{C}$ calcination temperature, and $\mathbf{d}$ at $650{ }^{\circ} \mathrm{C}$ calcination temperature 


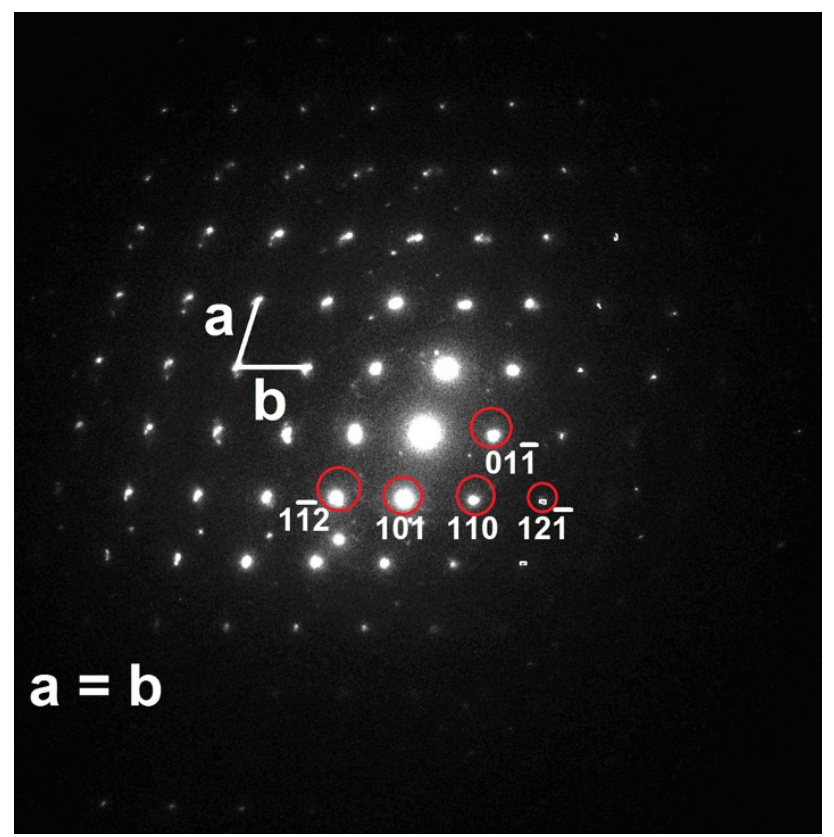

Fig. 7 TEM diffraction pattern of no-calcined $\mathrm{Dy}_{2} \mathrm{O}_{3}$ nanoparticles

increasing of the calcination temperature, which refers to the more crystalline structure.

\section{Transmission electron microscopy}

The morphology and size distribution of the no-calcined $\mathrm{Dy}_{2} \mathrm{O}_{3}$ and $\mathrm{Dy}_{2} \mathrm{O}_{3}$ samples calcined at 450, 550, and $650{ }^{\circ} \mathrm{C}$ are shown in Fig. 6. TEM images of the samples confirm the nano-size of the particles in the range of 10-90 $\mathrm{nm}$. The histograms show that the mean particle size of the no-calcined and calcined samples at 450, 550, and $650{ }^{\circ} \mathrm{C}$ are about $28,33,36$, and $41 \mathrm{~nm}$, respectively. It is clear from TEM images that the nanoparticles grew as the calcination temperature increased [9].

TEM images results like XRD (Scherer's formula) results confirm the nano-size of the particles of the samples, but TEM shows the mean size of the particles more accurately than XRD. This difference in the size refers to this fact that "TEM shows the size of the particles and XRD shows the size of the crystallites". In addition, the Scherer's formula (2) has good results for single crystals (our samples are not single crystals) and we use Scherer's formula (2) only to confirm the nano size of the samples before using TEM images [8]. Figure $5 \mathrm{~b}$ shows the variation of average particle size against the calcination temperatures obtained from the TEM results.

TEM electron diffraction or selected area electron diffraction (SAED) pattern of no-calcined $\mathrm{Dy}_{2} \mathrm{O}_{3}$ nanoparticles is shown in Fig. 7. Since, there is no significant variation in SAED pattern for other samples, only the SAED pattern of no-calcined sample is shown in this research. It is obvious from the ordered points that the crystal structure is formed and this pattern is for a single crystal. This pattern is related to one of the standard indexed diffraction patterns for bcc crystals in $[-111]$. The electron beam was perpendicular to the $\mathrm{Dy}_{2} \mathrm{O}_{3}$ (111) plane. Some spots are marked with (hkl) indices [10-12].

\section{Conclusions}

A novel approach for the synthesis of the dysprosium oxide nanoparticles has been developed without applying calcination temperature. It was observed from XRD results that all samples consist of no-calcined sample obtained directly from combustion method and calcined samples at 450, 550, and $650{ }^{\circ} \mathrm{C}$ exhibited cubic structure. The crystallite size was estimated by XRD, using Scherrer's formula (2), 24, 25,27 , and $28 \mathrm{~nm}$ for no-calcined sample and samples calcined at 450,550 , and $650{ }^{\circ} \mathrm{C}$, respectively. TEM and $\mathrm{XRD}$ results indicated that increasing the calcination temperature improved the crystallinity. TEM images show that the average diameter of no-calcined sample and samples calcined at 450,550 , and $650{ }^{\circ} \mathrm{C}$ are $28,33,36$, and $41 \mathrm{~nm}$, respectively. TEM electron diffraction (SAED) pattern of $\mathrm{Dy}_{2} \mathrm{O}_{3}$ nanoparticles shows one of the standard indexed diffraction patterns for bcc crystals in [-111].

Open Access This article is distributed under the terms of the Creative Commons Attribution License which permits any use, distribution, and reproduction in any medium, provided the original author(s) and the source are credited.

\section{References}

1. Boddu S (2011) Synthesis and characterization $f$ lanthanide ions doped nanomaterials. Bhabha Atomic research centre, $\mathrm{PhD}$ thesis

2. Happy Tok AIY, Su LT, Boey FYC, Ng SH (2007) Homogeneous precipitation of $\mathrm{Dy}_{2} \mathrm{O}_{3}$ nanoparticles-effects of synthesis parameters. J Nanosci Nanotechnol 7:1-9

3. Sato S, Takahashi R, Kobune M, Gotoh H (2009) Basic properties of rare earth oxides. Appl Catal A-Gen 356:57-63

4. Collusi S, Leitenburg CD, Dolcetti G, Rovarelli AT (2004) The role of rare earth oxides as promoters and stabilizers in combustion catalysts. J Alloy Compd 374:387-392

5. Kishi H, Mizuno Y, Chazono H (2003) Base-metal electrodemultilayer ceramic capacitors: past, present and future perspectives. Jpn J Appl Phys 42:1-15

6. 2010 Published by The US department of energy. Visit: http://ow. $1 \mathrm{y} / 3 \mathrm{pPdV}$

7. Klug P, Alexander LE (1954) Diffraction procedures for polycrystalline and amorphous materials, 1st edn. Wiley, New York, Chap 9: 903-700

8. Zelati A, Amirabadizadeh A, Kompany A (2011) Preparation and characterization of barium carbonate nanoparticles. Int $\mathrm{J}$ Chem Eng Appl 2:306-310 
9. Khorsand Zak A, Majid A, Abd WH, Darroudi M, Yousefi R (2011) Synthesis and characterization of $\mathrm{ZnO}$ nanoparticles prepared in gelatin media. Mater Lett 65:70-73

10. Srivastava AK, Kishore R, Swati Agnihorty SA (2004) Electron microscopy and diffraction analysis of nano-structured prussian blue thin films. Indian J Eng Mater Sci 11:315-318

11. Romeu D Gomez A Reyes-Gasga J: Electron diffraction and HRTEM structure analysis of nanowires, nanowires-fundamental research. 1st edn. Chap 20, Hashim A (ed), InTech 2011. www. intechopen.com/books/nanowires-fundamental-research/electron diffraction-and-hrtem-structure-analysis-of-nanowires

12. Basic crystallography and electron diffraction from crystals, CHEM 793, 2008 Fall, Lecture 14 nstg.nevada.edu/tem/chem 793-2011/Lecture_14_1_CHEM793.pdf 